\title{
Spectroscopic Analysis of the Interaction between Bovine Serum Protein and Lead Ion
}

\author{
Xiangqian Kong, Yingqing Liu,Yanhua Chen \\ School of Chemistry and Bioengineering, Jilin Medical University, Jilin, China
}

\begin{abstract}
In this paper, the spectral characteristics of the interaction between lead and bovine serum albumin (BSA) were analyzed by fluorescence spectroscopy, ultraviolet spectroscopy and infrared spectroscopy. The effects of $\mathrm{pH}$, bovine serum albumin concentration, lead ion concentration and ionic strength on the spectra of lead ion-bovine serum albumin system were investigated, and the best testing condition is to determine the interaction between lead and BSA by testing the peak changes or displacement in the UV spectrum analysis. Fluorescence spectroscopy showed that lead ion could induce the fluorescence quenching of bovine serum albumin. The influence of lead ion on the secondary structure of protein was analyzed by infrared spectroscopy. It was found that $\beta$-angle increased, $\alpha$-helix decreased and $\beta$-slice increased.
\end{abstract}

KEYWORDS: lead ion; bovine serum albumin; fluorescence spectroscopy; UV-visible spectroscopy; infrared spectroscopy

\section{Introduction}

In the organism, the proteins are a biologically important substances, it plays a key role in the movement and development of life. The study of the composition, conformation and interaction mechanism of small molecules is a common concern and interest of the staff who work in the field of chemistry, chemical biology, life sciences, pharmacy and clinical medicine technology. Serum albumin is carrier protein which is most abundantly in plasma, it can effectively combine with many endogenous substances and exogenous drugs and to form a complex, thus it directly or indirectly in regulating the role of protein [2-4] and affecting the physiological role of protein. Therefore, the study of the interaction between small molecules and biological macromolecules such as protein has attracted great attention. There is a wide variety of proteins, those has been found has reached millions, however various of the proteins are macromolecule polydentate ligands containing multiple coordination atoms (such as: N, O, S, some proteins also contain P, etc.) and thus it can easily interact with metal ions or their small molecule complexes and correspond to different spectral characteristics. The function of the protein is closely related to its structural conformation, different structures have different function of the protein, and vice versa. The activation or maintenance of a biological function is often associated with the role of some elements of life or beneficial elements; at the same time, the weakening or disappearance of a certain biological function or activity of the protein is often affected by some contaminated element or harmful element. Most of the elements are metal elements that stabilize or alter the structural conformation of the protein by the action of the associated protein, so as to achieve the purpose of controlling or affecting the function of the protein. Therefore, it can be said that the interaction of metal elements with protein, especially the interaction of many different metal elements with protein in near physiological environment and the change of protein structure before and after the action, elucidate the mechanism of the action of some metal elements, It is of great significance to study the effects of trace elements on human health, prevent poisoning and environmental pollution control from the molecular level.

Bovine serum albumin (BSA) is a commonly used in protein study because it is the most abundant carrier protein in plasma, able to react with many endogenous substances and exogenous substances in body, and BSA have been scanned and measured by X-ray [5-6]. Bovine serum albumin and human serum protein is very similar, both amino acid sequence is also very similar, bovine serum albumin is a biological organic macromolecules containing multi-

Copyright (C) 2017 -. This is an Open Access article distributed under the terms of the Creative Commons Attribution-NonCommercial 4.0 International License (http://creativecommons.org/licenses/by-nc/4.0/), permitting all non-commercial use, distribution, and reproduction in any medium, provided the original work is properly cited. 
coordination group, and can coordinated with metal ions. So the analysis of bovine serum albumin has a very important theoretical and practical significance.

The interaction of metal ions with protein is affected by the rigidity and flexibility of the protein itself, also affected by metal ion charge, radius, coordination configuration and other factors, such as Zn which always coordinated with Cys and His to form tetrahedral structure. In addition, the reaction temperature, reaction time, ion concentration (strength), acidity, buffer and etc. affect the protein and metal ions interaction. In particularly noteworthy that the effect of ion concentration on the reaction, the concentration is too high or too low will not achieve the desired experimental purposes, because both beneficial to the human body or harmful elements, they have a constant concentration in the body. Any kind of element concentration is too high or too low will have a negative impact on the human body, and the protein itself also exists salting out effect, so in the course of the experiment should choose a suitable ion concentration range. Lead is widely distributed in nature, and almost all minerals contain lead. Lead ion is commonly seen in life, lead is indispensable material in the industrial production and scientific research. It also plays an important role in human's production. But lead is one of the most harmful toxic elements in humans and higher class organisms. Lead pollution has caused a variety of disasters to humans. Lead is present in many forms in nature. Lead form is different, the toxicity is different. Studies have shown that inorganic lead can be generated into correspondence organic lead when react with biochemethylation, ethylation, and the organic lead can be absorbed by animals and plants, and through the food chain enrichment, and ultimately endangering human health. Lead can benefit to human, but will cause environmental pollution. Therefore, the detection method with high sensitivity and selectivity must be carried out to study lead which is theoretically and practically significance. The study of the interaction between proteins and metal ions has begun in the early 1950s. Since 1960s, many scientists have used crystal structure analysis and coordination chemistry to study the structure of some metalloproteins and metallases, and their bioactivity studies had speculated their mechanism of action. These studies together constitute the main elements of bioinorganic chemistry in research aspects. Since the 1980s, the development of various detection technologies and computer technology has opened a new situation in the study of the interaction between protein and metal ions. In this respect, Wang Kui and Shen Panwen have made a lot of research work, and there are a number of related monographs to introduce specific experiments. Commonly used detection methods are as follows:

\subsection{Ultraviolet spectroscopy}

Ultraviolet absorption spectroscopy is a common way to understand the conformation of protein molecules in solution. Bovine serum albumin molecules have a strong absorption peak at about $280 \mathrm{~nm}$. Due to the specific binding of different regions of the protein, binding with drugs results in the displacement of the absorption peak, a small amount of complex is added to the bovine serum albumin solution to observe whether the characteristic absorption peak of bovine serum albumin is displaced or peak changes can be a rough idea of whether the complex react with BSA.

Serum protein can absorb ultraviolet light, when it reacts with small molecules, the changes of correspondence displacement of absorption peak and peak width were observed. Du $\mathrm{Na} \mathrm{Na} \mathrm{Na} \mathrm{Na} \mathrm{Na} \mathrm{et} \mathrm{al.} \mathrm{studied} \mathrm{the} \mathrm{interaction}$ of Isoniazid (INH) and BSA by using UV absorption spectroscopy and fluorescence spectroscopy and the effect of fluorescence quenching mechanism of INH on BSA was discussed [7]. Lü Guiying et al. studied the interaction between bovine serum albumin and cadmium reagent $1 \mathrm{~B}$ in the presence of Tween $2 \mathrm{O}$ by UV-visible molecular absorption spectroscopy and established an analytical method for protein detection which applied in the products of bovine serum albumin test [8]. Zhang Hongmei et al. studied the interaction of rare earth element $\mathrm{Nd} 3+$ ions and bovine serum albumin (BSA) in microemulsion system at different $\mathrm{pH}$ values by using UV spectrum, and preliminary discussed the mechanism effect of $\mathrm{Nd} 3+$ and bovine serum albumin [9].

\subsection{Fluorescence spectrophotometry}

Fluorescence spectroscopy has the advantages of high sensitivity, good selectivity and low dosage used. The use of fluorescence spectroscopy in order to determine the role of drugs, rare earth metals and bovine serum albumin were reports [10-15]. Luo Hongbin et al. studied the interaction between bergenin and bovine serum albumin (BSA) molecules by fluorescence spectroscopy. The results showed that the binding constant of bergenin and BSA was 2.083 $\mathrm{x} 104$ and the number of binding sites was 1 [16]. Li et al. studied the interaction between Sorbito1 and bovine serum albumin (BSA) by fluorescence and ultraviolet absorption spectroscopy. The binding constants of the reaction at different temperatures were $7.4 \times 10-5(25 \mathrm{oC})$ and $1.7 \times 10-4(37 \mathrm{oC})$, respectively, and the total number of binding sites was 1 [17]. Wu et al. studied the interaction of antipyretic analgesics acetaminophen (PTL) and BSA by using fluorescence spectrophotometry and UV-visible spectrophotometry under simulation of human body's physiological environment. The results show that due to the fluorescence quenching which caused by non-radiative energy transfer, the fluorescence intensity of BSA is significantly reduced after binding with PTL. The experiment data were treated by using Stern-Volmer equation and Lineweaver-Burk equation, and the static equilibrium constant (KLB) of this binding reaction was found to be $2.592 \mathrm{X} 103 \mathrm{molL}-1(297 \mathrm{~K})$, and the binding position was $1.94 \mathrm{~nm}$ apart from the 212 sited tryptophan. According to the thermodynamic parameters of the binding reaction, it is concluded that the binding force 
between PTL and BSA was hydrophobic force (sulfur water force) $\square 1 \square$. The contents and methods of Fluorescence spectrum investigation are as follows:

(1) the determination of the binding site

The three-dimensional crystal structure of serum albumin has been shown, it consists of e three similar domains [18]: Sitel, Sitell and Site1H. Each domain also contains A and BZ subdomains, a cylindrical structure is formed in the manner like notch-opposing each other. Most of the drugs in serum albumin's binding site are Sitel and Sitdl. The following methods are commonly used to determine the binding sites of drug molecules on serum albumin by using fluorescence detection.

(2) Instead of using a probe with a known specific site [4-7]

Some fluorescent probes have specific binding site at different regions of the protein, and the drug binding sites can be determined based on the effect of the drug on the fluorescent probe. Known probes for Sitel are Warfarin, (Phnylbutazone), dansyl-lamide, etc.; Site11 probes are ibuprofen, flufenamic acid and so on.

(3) The distance between the drug and the tryptophan residue by Forster energy transfer theory [19-22]

The endogenous fluorescence of proteins is mainly caused by tryptophan. Using the Forster energy transfer theory, we can find the distance between the drug and the tryptophan residue, and speculate that the site where drug binds to the protein. The energy transfer can occur within a drug-protein complex, and can also occur between the drug and the protein molecule. In the latter case, the distance between the obtained drug and the tryptophan residue represents the closest distance between the drug molecule and the tryptophan residue during the molecular diffusion process [22].

(4) Determination of binding sites and binding constants

Scatchard is a classical method for studying the binding reaction of biological macromolecules to organic small molecules. This method should be used in the application of the known concentration of free drugs in the reaction system, which is often difficult to do with the fluorescence method, and Scatchard mapping results are often not ideal; therefore, in the study of drug molecules and protein binding reaction, application of Scatchard mapping method is not much. Zhang Baolin et al. used this method to study the anthraquinone and flavonoids and human serum albumin binding reaction $[11]$.

When the protein reacts with the drug molecule, it can cause the change of the fluorescence properties of the system. There are two cases: (1) the drug molecule does not have fluorescence and the endogenous fluorescence of the protein is quenched after adding the drug to the protein solution; (2) Drug molecules have fluorescence, but binding of protein and drug cause the endogenous fluorescence is quenched, while the fluorescence of drug molecules are sensitized enhanced. From the fluorescence quenching mechanism, the quenching of protein molecules by fluorescence can be divided into dynamic quenching and static quenching. Dynamic quenching is the fluorescence quenching caused by the interaction between the excited molecules of the drug and the protein, following the Stern-Volmer equation [9-10]:

$\mathrm{Fo} / \mathrm{F}=1+\mathrm{KsvCQ}$

Where Fo is the fluorescence intensity of the protein when no drug is added (quencher), $\mathrm{F}$ is the fluorescence intensity of the protein when the drug concentration is added, and Ksv is called the quenching constant. Static quenching is complexes of drugs and proteins in the ground state, resulting in decreased protein fluorescence intensity. For the case of 1: 1 combination, the formula was derived as:

$\mathrm{Fo} / \mathrm{F}=1+\mathrm{K}[\mathrm{Q}](2)$

Where $\mathrm{K}$ is the stability constant of the complex, and $[\mathrm{Q}]$ is the concentration of the free drug molecule. According to this formula for the Fo / F- [Q] graph, the K value can be obtained from the slope of the regression line. (2) is plotted and found that the regression line is often linearly poor. To this end, the equation (2) is transformed into a double reciprocal formula [12], which is the most commonly used formula for the domestic author.

$($ Fo - F) $-1=$ Fo -1 + K-1 Fo-1 [Q] -1 (3)

By comparing equations (1) and (2), it can be seen that there is a linear relationship between Fo / F and CQ, whether it is static quenching or dynamic quenching, and thus only by measuring the fluorescence intensity of the fluorescence quenching data, it cannot determine whether the quenching phenomenon is dynamic or static. Distinguish between dynamic quenching and static quenching can be determined by the following aspects:

(1) Dynamic quenching is related to temperature, and the increase of temperature will increase the diffusion coefficient, and increase the bimolecular quenching constant. The increase of temperature may cause the stability of the complex to decrease, and reduce the degree of static quenching. 
(2) Because the dynamic quenching only affects the excited state of the fluorescent molecules, it does not change the absorption spectrum of the fluorescent substance. In the static quenching, the formation of the ground complex often leads to the change of the absorption spectrum of the fluorescent substance.

(3) Static quenching, the presence of the quencher does not change the lifetime of the excited state of the fluorescent molecule, $\tau_{\mathrm{o}} / \tau=1$; and the dynamic quenching, the presence of the quencher reduces the fluorescence lifetime, $\tau \mathrm{o} / \tau=$ $\mathrm{Fo} / \mathrm{F}$ is the most accurate method to distinguish in between static quenching and dynamic quenching.

\subsection{Infrared spectroscopy}

The development of various experimental techniques provides a powerful tool for studying the relationship between the structure and function of proteins and polypeptides. The secondary structure of proteins is closely related to the different types of hydrogen bonds formed within the molecule. Infrared spectroscopy is an effective tool for studying the secondary structure and kinetic properties of proteins. [23] It is possible to study the structure and function of proteins by studying the relationship of secondary structure of proteins. Liu Huizhou et al. studied the effect of emulsification and secondary structure of lysozyme in aqueous surfactant solution by infrared spectroscopy. It was suggested that ionic surfactant and protein could destroy the ordered helical structure of protein molecules and increase the content of the random coil structure [19].

Infrared spectroscopy is one of the main methods to study the secondary structure of protein, which can qualitatively and quantitatively analyze the secondary structure of protein. In 1950, Elliott and Ambrose based on the model peptide proposed hypothesis where the infrared peptide I band $1660 \sim 1650 \mathrm{~cm}-1$ peak is belongs to $\alpha$-helix structure, $1640 \sim$ $1630 \mathrm{~cm}-1$ peak is belongs to $\beta$-fold conformation is the qualitative estimation of secondary structure of protein [ $87-$ 88]. In the mid-1970s, a number of semi-quantitative methods for calculating protein conformation were developed. The limitations of these methods were that they required many parameters, and the difficulty of practical work was the same. In 1983, Susi and Byler first applied the second derivative theory to the study of the secondary structure. In 1986, they applied the convolution method to the secondary structure analysis [89], which makes the secondary structure of the infrared protein into the quantitative stage.

The protein exhibits nine characteristic vibrational modes or group frequencies in the infrared region, where the most commonly used in secondary structure analysis is the amide I band located in the range of 1700 to $1600 \mathrm{~cm}-$ 1. As the protein contains a variety of different secondary structural units, these conformation corresponding to the vibration absorption peaks overlap together to form a broad peak, the inherent width of each sub-peak is greater than the instrument resolution, the use of ordinary spectrum technology is difficult to separate the sub-peaks, and Fourier transform infrared high resolution, high sensitivity, high signal to noise ratio and frequency accuracy and other characteristics, causing the second derivative, deconvolution technology can be applied to FTIR, which can separate the peak in amide I band which cannot be distinguished and the peak values of each sub-peak were pointed out, and then the components of the secondary structure of the protein were quantitatively analyzed by curve fitting.

At present, the study of small molecules, ions and albumin interaction method other than spectroscopy, the other common methods are balanced dialysis, nuclear magnetic resonance, centrifugal ultrafiltration and calorimetry [24].

Wang Kui et al., discovered the balance conditions, $\mathrm{pH}$ effects, as well as metal ions (including rare earth metal ions) of the coordinated metal ions and serum albumin with the main coordination group and position of protein through a series of experiment carried out[25].

In the above methods, the application of UV-visible spectroscopy and fluorescence spectrophotometry were used most in experiment, by using fluorescence method, it can be found that fluorescence quenching can occur on BSA due to non-radiation energy transfer, and the effects of the addition of other substances on the conformation of bovine serum albumin can be determined by calculating the equilibrium constant, the binding site, the type of the force, and the relevant thermodynamic constants. The study system is based on the drug, rare earth metal and bovine serum albumin. And the effect of lead ion on the conformation of bovine serum albumin and the interaction mechanism the two groups have not been reported. Therefore, high sensitivity and high selectivity detection method must be search in order to carry out the study which has theoretical and practical significance. 


\section{Experimental part}

\subsection{Experimental reagents and instruments}

\subsubsection{Experimental apparatus}

(1) 970CRT type fluorescence spectrophotometer (Shanghai analytical instrument factory)

(2) UV-7502PC type UV-Vis spectrophotometer (Shimadzu, Japan)

(3) Electronic balance (Beijing Sartorius Instrument Systems Co., Ltd.)

(4) $10-1000 \mu \mathrm{L}$ pipettes

(5) Nicolet6700 infrared spectrometer (American thermoelectric company)

\subsubsection{Experimental reagents}

Name, Purity and Specification Reagent Source

Bovine serum albumin biochemical reagents. Pharmaceutical Group Chemical Reagent Co., Ltd

Lead nitrate biochemical reagents. Pharmaceutical Group Chemical Reagent Co., Ltd

Analysis of pure phosphate chemical reagents

Potassium Dihydrogen Phosphate Analysis Pure Pharmaceutical Group Chemical Reagent Co., Ltd

Secondary distilled water

Sodium Chloride Analysis Pure Guodu Chemical Reagent Co., Ltd

\subsection{Preparation of the solution}

\subsubsection{Preparation of buffer}

KH2PO4 and Na2HPO4 were accurately weighed to $0.9073 \mathrm{~g}$ and $2.3852 \mathrm{~g}$ respectively. $1 / 15 \mathrm{~mol} / \mathrm{L}$ of the buffer was made in $100 \mathrm{ml}$ volumetric flask and the $\mathrm{pH}$ was adjusted to $6.0,6.5,7.0,7.5,8.0$ and 8.5.

\subsubsection{Preparation of BSA solution}

Take $50 \mathrm{ml}$ volumetric flask, weigh $0.3400 \mathrm{~g}$ bovine serum albumin, with secondary distilled water into $1 \times 10-4 \mathrm{~mol}$ $\mathrm{L}$ bovine serum albumin solution, and diluted to $10-5 \mathrm{~mol} / \mathrm{L}$, as stock and stored into the refrigerator at below $5{ }^{\circ} \mathrm{C}$.

\subsubsection{Preparation of lead ion concentration}

$0.3312 \mathrm{~g}$ of lead nitrate was accurately weighed with an analytical balance and formulated into solution with concentration of $0.01 \mathrm{ml} / \mathrm{L}$ in $100 \mathrm{ml}$ volumetric flask. And then diluted with secondary distilled water into $1 \times 10-3$ $\mathrm{mol} / \mathrm{L}, 5 \times 10-4 \mathrm{~mol} / \mathrm{L}, 1 \times 10-4 \mathrm{~mol} / \mathrm{L}, 1 \times 10-5 \mathrm{~mol} / \mathrm{L}, 5 \times 10-5 \mathrm{~mol} / \mathrm{L}, 1 \times 10-6 \mathrm{~mol} / \mathrm{L}$.

(1) the preparation of different concentrations of lead nitrate solution

Take $10 \mathrm{ml}$ clean cuvette, add $2 \mathrm{ml}$ of BSA solution, $2 \mathrm{mlpH}=7.1$ buffer, add lead nitrate volume $(\mathrm{ml})$ as follows, and dilute with distilled water to $10 \mathrm{ml}$. 


\begin{tabular}{|c|c|c|c|c|c|c|}
\hline $\begin{array}{c}\text { Step } \\
\text { Concentration mol/L }\end{array}$ & $10^{-3}$ & $5 \times 10^{-4}$ & $10^{-4}$ & $10^{-5}$ & $5 \times 10^{-5}$ & $1 \times 10^{-6}$ \\
\hline 1 & 2.0 & 0.0 & 0.0 & 0.0 & 0.0 & 0.0 \\
\hline 2 & 4.0 & 0.0 & 0.0 & 0.0 & 0.0 & 0.0 \\
\hline 3 & 0.0 & 1.0 & 0.0 & 0.0 & 0.0 & 0.0 \\
\hline 4 & 0.0 & 0.0 & 2.0 & 0.0 & 0.0 & 0.0 \\
\hline 5 & 0.0 & 0.0 & 4.0 & 0.0 & 0.0 & 0.0 \\
\hline 6 & 0.0 & 0.0 & 0.0 & 2.0 & 0.0 & 0.0 \\
\hline 7 & 0.0 & 0.0 & 0.0 & 4.0 & 0.0 & 0.0 \\
\hline 8 & 0.0 & 0.0 & 0.0 & 0.0 & 1.0 & 0.0 \\
\hline 9 & 0.0 & 0.0 & 0.0 & 0.0 & 0.0 & 1.0 \\
\hline 10 & 0.0 & 0.0 & 0.0 & 0.0 & 0.0 & 2.0 \\
\hline 11 & 0.0 & 0.0 & 0.0 & 0.0 & 0.0 & 4.0 \\
\hline 12 & 0.0 & 0.0 & 0.0 & 0.0 & 0.0 & 0.0 \\
\hline
\end{tabular}

(2) Different $\mathrm{pH}$ solution preparation

Take a number of colorimetric tubes, add $2 \mathrm{ml}$ of BSA solution, and then add $2 \mathrm{mlpH}$ in $6.0,6.5,7.0,7.5,8,8.5$ buffer, and diluted with distilled water to $10 \mathrm{ml}$.

(3) The preparation of different concentrations of BSA concentration

In 11 clean $10 \mathrm{ml}$ colorimetric tubes, add $2 \mathrm{ml}$ of $2 \mathrm{mlpH}=7.1$ buffer, $2 \mathrm{ml} \mathrm{x} 4$ x 10-4 mol / L added into the BSA solution as shown in the following table, dilute to $10 \mathrm{~mL}$ with distilled water

\begin{tabular}{|l|l|l|l|}
\hline Step & $10^{-5} \mathrm{~mol} / \mathrm{L}(\mathrm{mL})$ & $1 \times 10^{-4} \mathrm{~mol} / \mathrm{L}$ & $4 \times 10^{-4} \mathrm{~mol} / \mathrm{L}$ \\
\hline 1 & 1.0 & 0.0 & 0.0 \\
\hline 2 & 2.0 & 0.0 & 0.0 \\
\hline 3 & 3.0 & 0.0 & 0.0 \\
\hline 4 & 4.0 & 0.0 & 0.0 \\
\hline 5 & 0.0 & 1.0 & 0.0 \\
\hline 6 & 0.0 & 2.0 & 0.0 \\
\hline 7 & 0.0 & 3.0 & 0.0 \\
\hline 8 & 0.0 & 4.0 & 0.0 \\
\hline 9 & 0.0 & 0.0 & 2.0 \\
\hline 10 & 0.0 & 0.0 & 3.0 \\
\hline 11 & 0.0 & 0.0 & 4.0 \\
\hline
\end{tabular}

(4) Measurement step:

Fluorescence: The emission wavelength was set at $350 \mathrm{~nm}$ and the fluorescence spectrum at 200-600 nm was measured. All measurements were made at room temperature $\left(15 \pm 2^{\circ} \mathrm{C}\right)$. Excitation and emission monochromator slits are $5 \mathrm{~nm}$.

UV: secondary distilled water was used as blank, scanning range 200-600nm.

Infrared: sensitivity set to $2 \mathrm{~cm}-1$, spectrum measurement in the range of $4000-400 \mathrm{~cm}-1$

\section{Results and discussion}

\subsection{Ultraviolet spectrum}

\subsubsection{UV spectra of the system at different $\mathrm{pH}$ conditions}




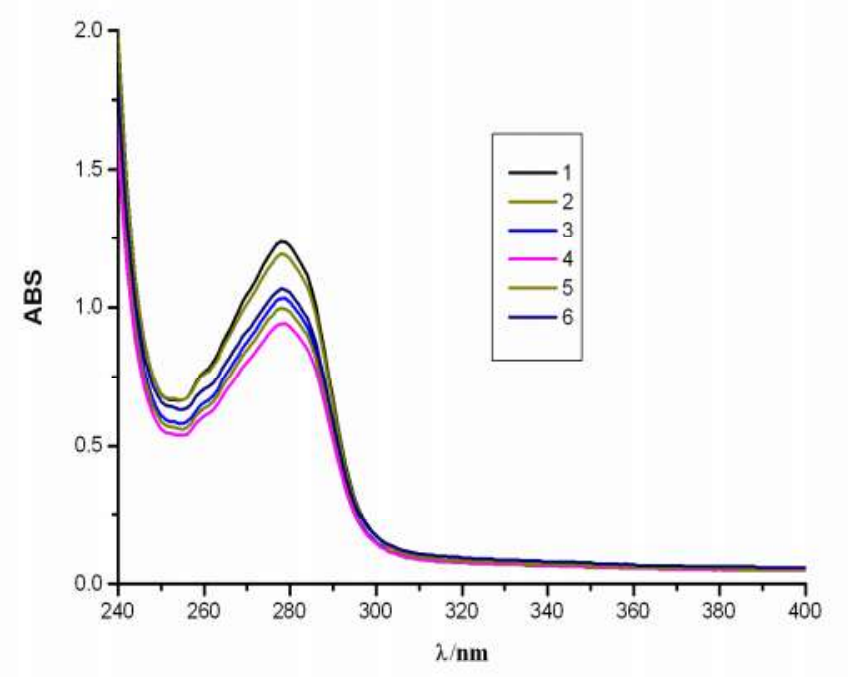

1-6: $\mathrm{pH}$, respectively, $6.0,6.5,7.0,7.5,8.0,8.5$

As the protein contains aromatic amino acid side chain, mainly tyrosine (Tyr), tryptophan (Trp), followed by phenylalanine (Phe) [27], they produce absorption near $285 \mathrm{~nm}$, thus the structure of protein can be studied by using UVvisible spectral.

Figure showed that the peak intensity is weakest at $\mathrm{pH}=7.5$. After $\mathrm{pH}>7.5$, the peak intensity decreases with the increase of $\mathrm{pH}$ value, and the absorption peak increases with $\mathrm{pH}$ at $\mathrm{pH}<7.5$. Proteins have carboxyl and amino groups as functional groups, so the $\mathrm{pH}$ changes are very sensitive, too acid and alkali will lead to protein degeneration and inactivation. The absorption peak near $280 \mathrm{~nm}$ of serum albumin is caused by the $\pi-\pi *$ transition of the aromatic heterocyclic ring of two tryptophan and 19 tyrosine residues on its peptide chain, while the absorption near $240 \mathrm{~nm}$ is mainly peptide bond $\mathrm{C}=\mathrm{N}-\pi *$ transition of the $\mathrm{O}$-based, it is related to the content of $\alpha$-helix structure of the protein molecule. After isoelectric point of BSA, with the decrease of $\mathrm{pH}$ in the system, the interaction between BSA molecules is enhanced, which is beneficial to the cohesion between molecules and molecules, causing the conformation of protein molecules changes, $\alpha$-helix content decreases and thus causing the absorption peak which nearby $240 \mathrm{~nm}$ is redshift. At the same time, due to the decrease of the $\mathrm{pH}$ value in the system, the phenomenon of peptide chain extension occur, the structure of serum albumin changes, causing the aromatic heterocyclic hydrophobic groups from tryptophan and tyrosine residues which enclosed within the albumin molecule are exposed. The interaction between the hydrophobic groups is enhanced and the transition energy increases, resulting in a red shift of the $285 \mathrm{~nm}$ absorption peak [26].

In the literature, [27], the major binding sites in the BSA molecule are at the N-terminus of the BSA at 56-57 (AspAsp), 170-171 (Glu-Asp), 362-363 (Asp-Asp) and 560 -561 (Asp-Asp) amino acid carboxyl group, while the other parts of the residual-COO-based are weak binding site. Since the coordination of these points causes the BSA conformational change, the $\alpha$-helix content decreases, resulting in a red shift in the absorption peak position.

\subsubsection{UV spectra of BSA under different concentrations}

1-12 BSA concentration of $1 \times 10-5 \mathrm{~mol} / \mathrm{L}, 2 \times 10-5 \mathrm{~mol} / \mathrm{L}, 3 \times 10-5 \mathrm{~mol} / \mathrm{L}, 4 \times 10-5 \mathrm{~mol} / \mathrm{L}, 1 \times 10-4 \mathrm{~mol} / \mathrm{L}, 2$ $\times 10-4 \mathrm{~mol} / \mathrm{L}, 3 \times 10-4 \mathrm{~mol} / \mathrm{L}, 4 \times 10-4 \mathrm{~mol} / \mathrm{L}, 8 \times 10-4 \mathrm{~mol} / \mathrm{L}, 1.2 \times 10-3 \mathrm{~mol} / \mathrm{L}, 1.6 \times 10-3 \mathrm{Mol} / \mathrm{L}, 2.0 \times 10-3$ $\mathrm{mol} / \mathrm{L}$

From the figure can be observed in the BSA concentration of $3 \times 10-5 \mathrm{~mol} / \mathrm{L}$ showed the maximum absorbance. 


\subsection{1.3 UV spectra of different concentrations of lead nitrate}
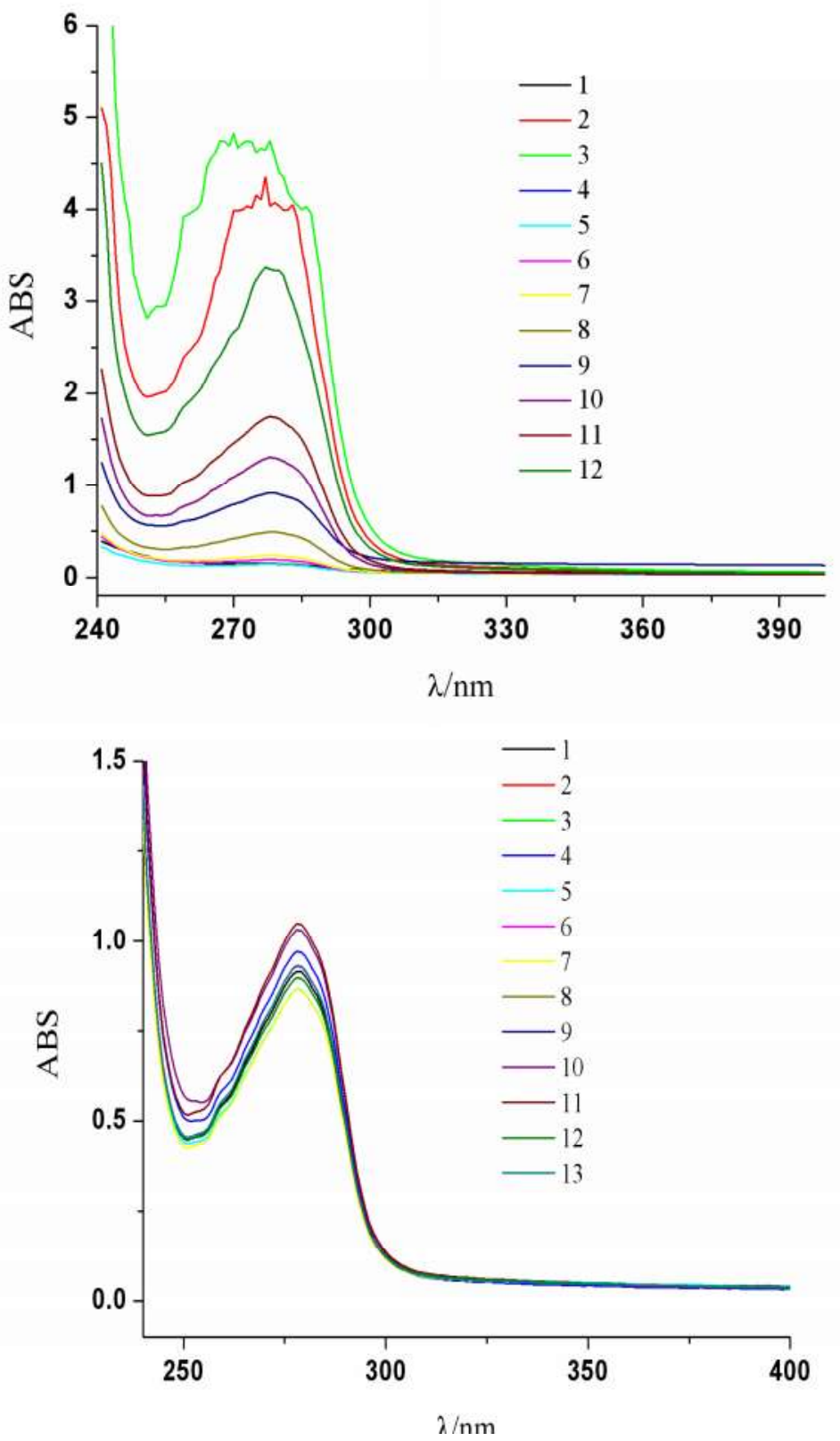

1-13 lead concentration: $0,1 \times 10-6 \mathrm{~mol} / \mathrm{L}, 2 \times 10-6 \mathrm{~mol} / \mathrm{L}, 3 \times 10-6 \mathrm{~mol} / \mathrm{L}, 1 \times 10-5 \mathrm{~mol} / \mathrm{L}, 2 \times 10-5 \mathrm{~mol} / \mathrm{L}, 4$ $\times 10-5 \mathrm{~mol} / \mathrm{L}, 5 \times 10-5 \mathrm{~mol} / \mathrm{L}, 2 \times 10-4 \mathrm{~mol} / \mathrm{L}, 4 \times 10-4 \mathrm{~mol} / \mathrm{L}, 2 \times 10-3 \mathrm{~mol} / \mathrm{L}, 10-3 \mathrm{~mol} / \mathrm{L}, 2 \times 10-2 \mathrm{~mol} / \mathrm{L}$

The peak position of the protein was $285 \mathrm{~nm}$. With the increase of lead concentration, the absorption peak near 285 nm was caused by the transition of ring $\pi-\pi *$ from the tryptophan and tyrosine on the peptide bond. When lead ions are added, lead ions bind to BSA to alter the molecular conformation of the protein. 


\subsubsection{Effects of ionic strength}

The concentration of 1-8Nacl was $0,0015 \mathrm{~mol} / \mathrm{L}, 0.003 \mathrm{~mol} / \mathrm{L}, 0.0045 \mathrm{~mol} / \mathrm{L}, 0.002 \mathrm{~mol} / \mathrm{L}, 0.0025 \mathrm{~mol} / \mathrm{L}, 0.005$ $\mathrm{mol} / \mathrm{L}, 0.01 \mathrm{~mol} / \mathrm{L}, 0.015 \mathrm{~mol} / \mathrm{L}$

It can be seen that when the concentration of $\mathrm{Nacl}$ is $0.0045 \mathrm{~mol} / \mathrm{L}$, the fluorescence spectra of the system are stable and the absorbance is large. Therefore, the concentration of $\mathrm{Nacl}$ at $0.0045 \mathrm{~mol} / \mathrm{L}$ was selected as experiment standard concentration.

The ion concentration has a great effect on the reaction of lead and bovine serum albumin, and the ion concentration is too high or too low will not achieve the desired experimental purpose, because both are beneficial and harmful elements of the human body, they have a considerable constant concentration range, any one element too high or too low will have a negative impact on the human body, and the protein itself also exists salting out, so in the course of the experiment should choose a suitable ion concentration range in order to get better experimental results.

\subsection{Fluorescence patterns}

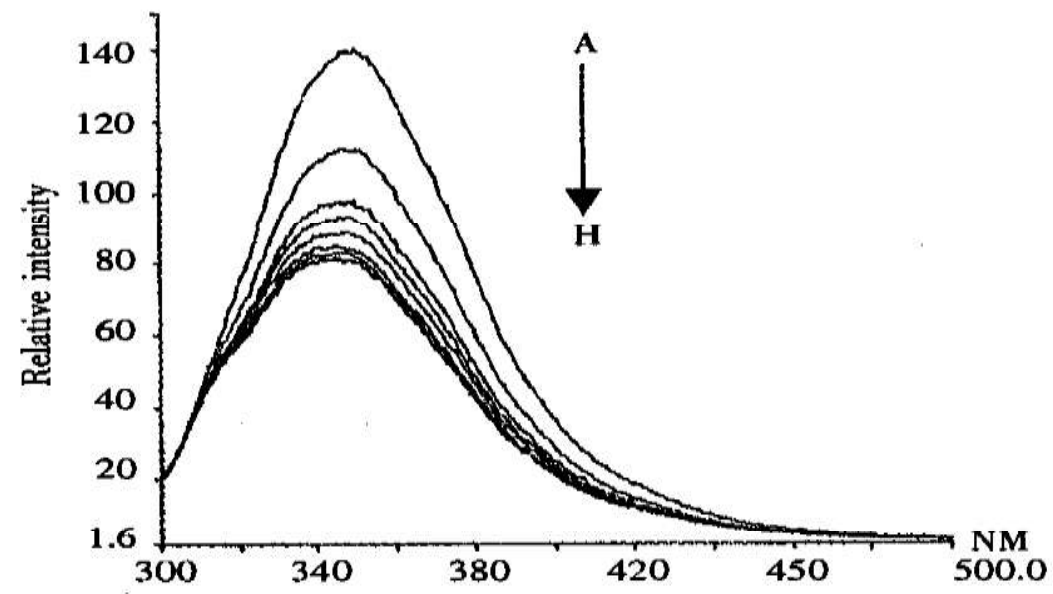

A-H lead ion concentration of $0,1 \times 10-6 \mathrm{~mol} / \mathrm{L}, 2 \times 10-6 \mathrm{~mol} / \mathrm{L}$,

1 × 10-5 mol / L, 2 × 10-5 mol / L, 2 × 10-4 mol / L, 4 × 10-4 mol / L, 2 × 10-3 mol / L 
The endogenous fluorescence of proteins is mainly derived from the tryptophan residues and tyrosine residues in the molecule, and the fluorescence is mainly from the 212th tryptophan residue. At $280 \mathrm{~nm}$, the endogenous fluorescence emission peak in the BSA molecule is near $350 \mathrm{~nm}$. The figure shows the change of the fluorescence spectrum of the fixed BSA concentration and the fluorescence emission spectrum of the system with the change of the lead ion concentration. Figure showed that the peak shape has no significant change with the increase of the lead ion content, but the emission wavelength has blue shift $(5 \mathrm{~nm})$, the fluorescence intensity is regularly reduced, indicating that the effect of lead ions on the fluorescence of BSA quenching.

\subsection{Infrared spectra}

The secondary structure of the protein refers to the folding of the polypeptide chain itself in the protein molecule, such as $\alpha$-helix, $\beta$-sheet, $\beta$-turn, etc., amide I band and amide III band $(1240 \mathrm{~cm}-1)$, to a certain extent it reflect the changes of protein secondary structure, and the amide I band is more sensitive to the secondary structure of the protein molecule, and the change of the amide I band can approximately to characterize the type of secondary structure of the protein molecule.

Characteristic vibrations of amide groups

\begin{tabular}{|l|c|c|}
\hline Name & wavenumber $/ \mathrm{cm}^{-1}$ & vibration mode \\
\hline Amide A & 3300 & N-H stretching vibration \\
\hline Amide B & 3100 & $\begin{array}{l}\text { amide II band with a pan-frequency, } \\
\text { Fermi resonance }\end{array}$ \\
\hline Amide I & 1660 & $\mathrm{C}=$ O stretching vibration \\
\hline Amide II & 1570 & $\begin{array}{c}\text { N-H in-plane bending vibration and } \\
\text { C-N stretching vibration }\end{array}$ \\
\hline Amide III & 1300 & $\begin{array}{c}\text { C-N stretching vibration and N-H } \\
\text { in-plane bending vibration }\end{array}$ \\
\hline Amide IV & 630 & C-N in-plane bending vibration \\
\hline Amide V & 730 & N-H Outside Bending Vibration \\
\hline Amide VI & 600 & C = O Outside bending vibration \\
\hline
\end{tabular}

\begin{tabular}{|l|l|}
\hline Absorption peak position $/ \mathrm{cm}-1$ & Attribution \\
\hline $1600-1640$ & beta-fold \\
\hline $1640-1650$ & No return curl \\
\hline $1650-1670$ & $\alpha$-helix \\
\hline $1680-1685$ & Corner structure \\
\hline
\end{tabular}

\begin{tabular}{|c|c|c|c|c|c|c|}
\hline $\begin{array}{c}\mathrm{P} \mathrm{e} \mathrm{a} \mathrm{k} \\
\text { position } / \mathrm{cm}^{-1}\end{array}$ & 16751679 & 16521655 & 1645 & 16321630 & 1618 & 1614 \\
\hline Identify & $\beta$-turn & $\alpha$-helix & No-curled & $\beta$-chain & $\beta$-fold & Beta-sheet \\
\hline
\end{tabular}




Protein solid and aqueous solution, heavy water solution in the secondary structure of the main frequency / cm-1
\begin{tabular}{|l|l|l|l|}
\hline Structural components & Solid aqueous & Solution * & Heavy water solution * \\
& & & \\
\hline a-helix & $1646+1.0$ & $1656+2.0$ & $1653+4.0$ \\
\hline a-helix & $1653+3.0$ & $/$ & $/$ \\
\hline a-helix & $1635+1.0$ & $/$ & $/$ \\
\hline B-sheet & $1620+2.0$ & $1624+0.5$ & $1624+4.0$ \\
\hline B-sheet & $/$ & $1632+1.0$ & $1631+3.0$ \\
\hline B-sheet & $/$ & $1638+1.0$ & $1637+3.0$ \\
\hline Corner & $1690+1.0$ & $1666+1.0$ & $1663+4.0$ \\
\hline Corner & $1668+1.0$ & $1672+1.0$ & $1671+3.0$ \\
\hline Corner & $1683+1.0$ & $1680+1.0$ & $1683+2.0$ \\
\hline Corner & $1675+1.0$ & $1688+1.0$ & $1689+2.0$ \\
\hline Corner & $1694+0.5$ & & $1694+2.0$ \\
\hline Disordered structure & $/$ & $1650+1.0$ & $1645+4.0$ \\
\hline
\end{tabular}

Note: * Data sources see 'Protein Structure Analysis', Yan Longfei Sun Zhirong editor, Tsinghua University Press, 1999, Beijing

\subsubsection{Infrared spectra of lead ions}

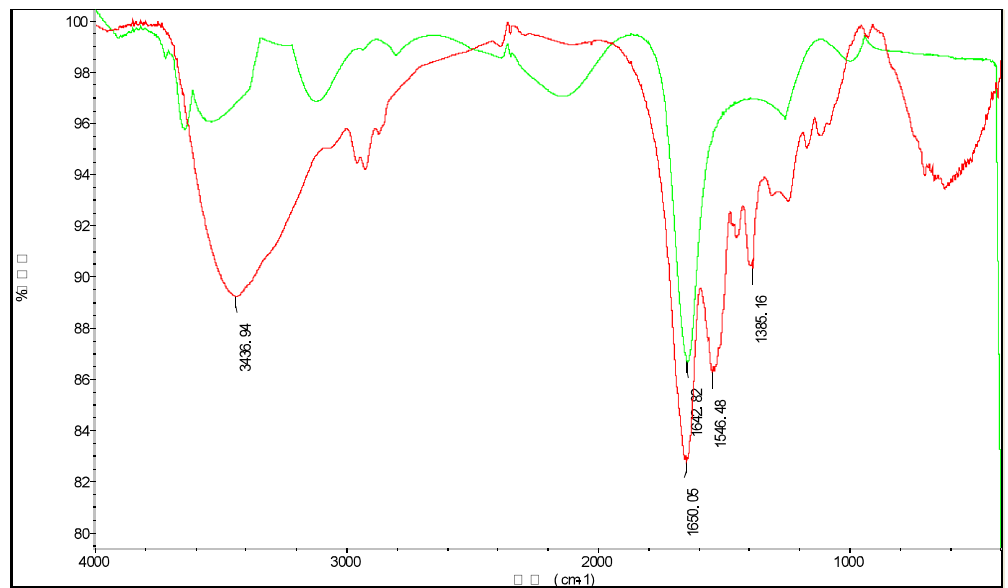

- Bovine serum albumin solution

- Bovine serum albumin solution containing 4 x 10-4 mol / Lb ions

BSA buffer were added to different concentrations of lead ions, other conditions remain unchanged. When the $\mathrm{Pb}$ ion is added, the relative intensity of BSA amide I band with $1650 \mathrm{~cm}-1$ and II with $1546 \mathrm{~cm}-1$ is obviously changed indicating that $\mathrm{BSA}$ and $\mathrm{Pb}$ ion reaction, $\mathrm{BSA}$ molecular structure has changed.

The BSA has three possible binding sites, namely the carboxyl group of oxygen, the nitrogen of the amino group and the nitrogen of the acyl group. The strong absorption peak at $1615.45 \mathrm{~cm}-1$ in the complex can be attributed to the antisymmetric stretching vibration of COO- in the side chain COO- or its metal complex COOM, while the peak at 1739.57 $\mathrm{cm}-1$ is formed by the side chain $\mathrm{COOH}$ or The $\mathrm{C}=\mathrm{O}$ stretching vibration in COOR corresponds to a weak broad peak at $1732.29 \mathrm{~cm}-1$ in hemoglobin.

These indicate that the combination of lead ions causes a large change in the secondary structure of hemoglobin and that lead ions may bind to the carbonyl or carboxyl groups of the amino acid residues.

\subsubsection{Infrared second derivative}




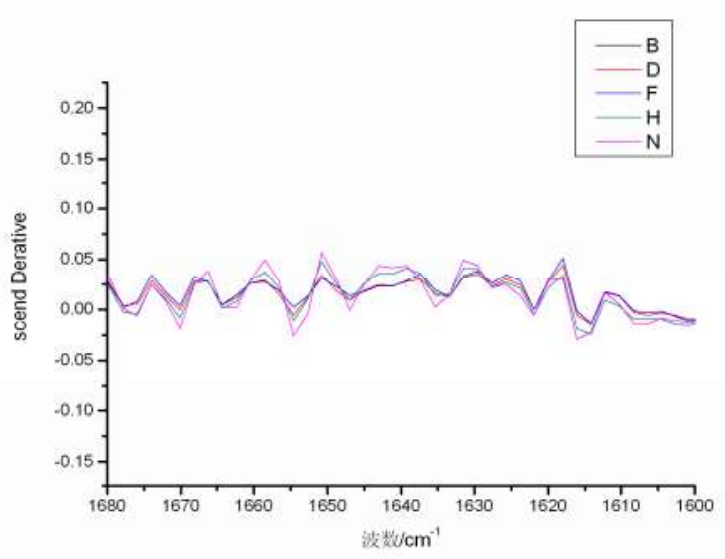

The concentration of B-N ions was $1 \times 10-6 \mathrm{~mol} / \mathrm{L}, 2 \times 10-6 \mathrm{~mol} / \mathrm{L}, 3 \times 10-5 \mathrm{~mol} / \mathrm{L}$, $2 \times 10-4,2 \times 10-3 \mathrm{~mol} / \mathrm{L}$

Infrared Spectroscopy of protein secondary structure indicates that the $1675 \mathrm{~cm}-1$ is a beta-turn at the $1655 \mathrm{~cm}-1$ alpha-helix, the $1614 \mathrm{~cm}-1$ is a beta-sheet, and the $1618 \mathrm{~cm}-1$ is a beta-fold. From the figure, it can be observed that the $\beta$-turn increases, the $\alpha$-helix decreases, the $\beta$-slice increases, and the $\beta$-sheet increases.

This result further suggests that lead and bovine serum albumin interact with each other, leading to the partial development of peptide chains in the protein molecule, altering the secondary structure of bovine serum albumin.

\section{Conclusion}

Preliminary conclude that the interaction of lead ion and BSA occurs and the coordination happened at the amino acid residues on the carbonyl or carboxyl group through the analysis of UV, fluorescent and infrared spectral.

The UV spectrum can only show the characteristic absorption band of the protein and the peak position is $285 \mathrm{~nm}$.

Lead ions can cause fluorescence quenching in bovine serum albumin, and the endogenous fluorescence emission peak in BSA molecule is near $350 \mathrm{~nm}$. The fluorescence intensity of the fluorescence emission spectrum decreases with the increase of lead ion concentration, but the emission wavelength has a blue shift trend (5nm), and the fluorescence intensity decreases regularly with the increase of lead ion concentration indicating that lead ions has fluorescence quenching effect on BSA.

After adding lead ions, there are changes in the relative intensities of BSA amide I band with $1650 \mathrm{~cm}-1$ and II with $1546 \mathrm{~cm}-1$ can be observed from the infrared spectrum. In the second derivative diagram, the $\beta$-angle increase of BSA in the presence of lead ions, $\alpha$-helix decreased, $\beta$-slice increased, to some extent it changed the secondary structure of BSA.

\section{References}

1. Wu G, Yan C, Liu Y. The interaction between phthalocyanine phenol and bovine serum albumin by fluorescence spectrophotometry [J]. Acta Metallurgica Sinica, 2007,43 (11): 964 (in Chinese with English abstract) -967.

2. FENG Xi-zeng, JIN Rui-xiang, QU Yun, et al. Chem. J. ChineseUniversities (Journal of Chemical Engineering of Colleges and Universities, 1996,17 (6): 866.

3. TANG Bo, HE Xiwen, SHEN Han-xi. Spectroscopy and Spectral Analysis, 1998, 18 (1): 21.

4. YAN Zheng-yu, PANG Daiwen, SHAO Xiufen, et al. Journal of China Pharmaceutical University, 2005,36 (3): $230-231$.

5. An Xiulin, Li Qingzhong, Liu Haiping, Zhang Guirong. Infrared Spectra Studies on the Interaction of Cetyltrimethylammonium Bromide with Bovine Serum Albumin [J]. Journal of Southwest China Normal University (Natural Science Edition) 30 (4): 700-702.

6. Santos SF, Zanette D, Fischer H, et al. A Systematic Study of Bovine Serum Albumin (BSA) and Sodium Dodecyl Sufate (SDS) Interactions by Surface Tensionand Small angleX-rayrabattering [J]. Journal of Colloid and Interface Science, 2003, 262: 400408. 
7. DU Nana, ZHANG Kun, XIE Yueqin, YANG Song, SHENG Liangquan. Spectroscopic Studies on the Interaction of Isoniazid and Bovine Serum Proteins [J]. Journal of Anhui University (Natural Science Edition), 2008,32 (4): 69 -72.

8. LU Gui-ying, WANG Ying, LV Jian-quan. Study on the Interaction of Bovine Serum Albumin with Cadmium Reagent 1B in the Presence of Tween 20 by Spectroscopic Method [J]. Spectroscopic Experiments, 2008,25 (3): 496-497.

9. (III) and bovine serum albumin in microemulsion system [J]. Journal of Guizhou University (Natural Science Edition), 2004,21 (1): 65-67 (in Chinese with English abstract) The

10. ZHOU Hong CHEN Chang-yun XIE An-jian. Study on the binding of fenbuterol hydrochloride to bovine serum albumin by spectroscopic method [J]. Spectroscopy and Spectral Analysis. 2007, 18; 1830-1833.

11. WANG An-ping, DING Yong, ZHANG Guo-wen, LIU Zhi-bin Studies on the Interaction of Sulfonamidone and Bovine Serum Albumin by Fluorescence Spectroscopy [J]. Journal of Nanchang University, 2007,29 (3).

12. YANG Chang-ying LIU Yi ZHU Jun-cheng LIU Song-xiu. Study on the Interaction of Indomethacin, Sulindac and Its Metal Complexes with Bovine Serum Proteins by Spectroscopic Method [J]. Chinese Journal of Analytical Chemistry, 200836 (4): 473-477 The

13. ournal of Yangzhou Teachers College: Natural Science Edition, 1997, 17 (1): 69-70. [J]. Journal of Yangzhou Teachers College (Natural Science Edition), 1997, 17 (1): 69-70.

14. YANG Chang-ying LIU Yi ZHU Jun-cheng LIU Song-xiu. Study on the Interaction of Indomethacin, Sulindac and Its Metal Complexes with Bovine Serum Proteins by Spectroscopic Method [J]. Chinese Journal of Analytical Chemistry, 200836 (4): 473-477 The

15. Liu Xiang, Zhu Xianyan. Advances in protein family of anti-heavy metal ions [J] .Analysis of Anhui Agricultural Science, 2007 (9): 32-34.

16. LUO Hong-bin, ZHANG Jing, CHEN Jing-hua, LI Guang-wen, LIN Xiao-yan Fluorescence spectroscopy study on the interaction between bergenin and bovine serum albumin [J]. Chinese Journal of Chemical Research, 2007,18 (3)

17. Li Dan, Jiang Xinmin, Yan Zhengyu. Study on the Interaction of Sorbitol with Bovine Serum Albumin by Fluorescence Spectroscopy [J]. Spectroscopy and Spectral Analysis, 2008,28 (6): 1312-1316.

18. KRAGH-HANSEN U. Molecular of ligand binding to serum albumin. Pharmacol. Rev, 1981, 33 (1), 17-53.

19. Wu P, BRAND L. Resonance energy transfer: methods and applications. Anal Biochem, 1994, 218, 1-13.

20. KASAIS, HORIE T, MIZUMA T, et al. Fluorescence energy transfer study of the relationship between the lone tryptophan residue and drug binding sites in human serum albumin. Journal of pharmaceutical sciences, 1987, 76 (5): 387-392

21. Ma Guibin, Yang Feng. Energy transfer technology and its application in microstructure analysis of solution molecules. Chemical Bulletin, 1993 (3), 29-32.

22. Zhang Xiaowei, Zhao Fenglin, Li Kean. Ciprofloxacin and bovine serum albumin interaction [J]. Journal of Chemical Engineering, 1999,20 (7), 1063-1067.

23. Yuan Bo, Yan Huimin. Study on thermodynamics process of bovine serum albumin by infrared spectroscopy and asymptotic factor analysis [J]. Journal of Infrared and Millimeter Waves, 2007,26 (4): 266-268.

24. Study on the Interaction of Anionic Surfactant SDS with Bovine Serum Albumin by Fourier Transform Infrared Spectroscopy [J]. Chinese Journal of Spectroscopy and Spectroscopy, 2006, 26 (9): 1598-1600.

25. HU Jun-cheng, ZHANG Rui, ZHAN Zheng-kun, XU Ming-fei, WAN Hong-wen. Study on the thermochemical study of the interaction between protein and copper ion [J]. Journal of Huazhong Normal University (Natural Science Edition), 2000,2 (1): $512-596$.

26. HuiXu, Quanwen Liu, Yanqing Wen. Spectroscopic studies on the interaction between nicotinamide and bovine serum albumin [J]. Spectrochimica Acta Part A 71 2008:984-988.

27. HuiXu, Shu-Li Gao, Ju-Bo Lv, Quan-Wen Liu, Ying Zuo, Xin Wang.Spectroscopic investigations on the mechanism of interaction of crystal violet with bovine serum albumin [J]. Journal of Molecular Structure 2009:334-338. 